\title{
Erratum: The Transition from Internal Oxidation to Continuous Film Formation during Oxidation of Dilute Ni-Si Alloys*
}

D. L. Douglass, P. Nanni, C. De Asmundis, and C. Bottino

Parts of Figure 8 on p. 327 were illegible. A clearer figure appears below.

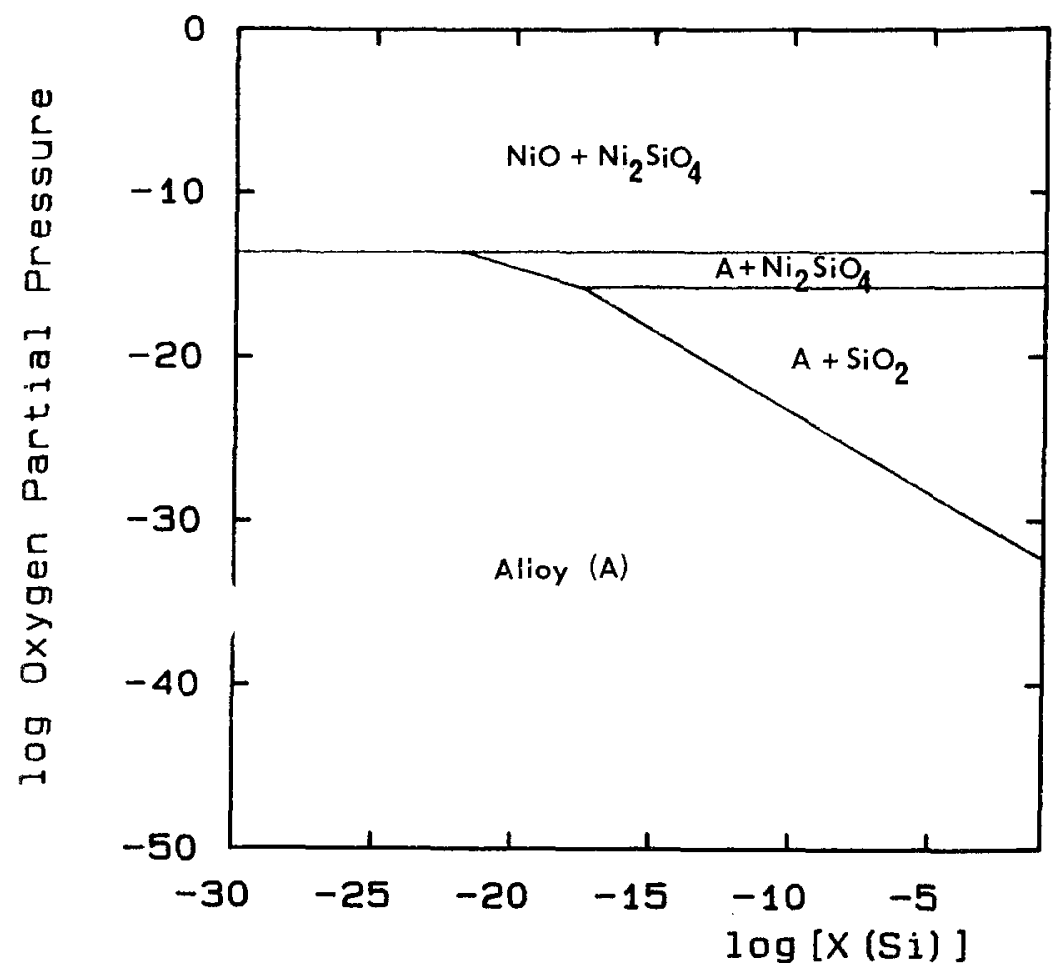

Fig. 8. Calculated stability diagram, Ni-Si-O at $800^{\circ} \mathrm{C}$.

*This paper originally appeared in Oxid. Met., 28, 309. 